\title{
Perceived Neighborhood Disorder, Community Cohesion, and PTSD Symptoms Among Low-Income African Americans in an Urban Health Setting
}

\author{
Mark Gapen, Dorthie Cross, Kile Ortigo, Allen \\ Graham, Eboni Johnson, Mark Evces \\ Emory University
}

\author{
Kerry J. Ressler \\ Howard Hughes Medical Institute and Emory University
}

\author{
Bekh Bradley \\ The Atlanta VA Medical Center and Emory University
}

\begin{abstract}
Studies have established a link between contextual factors, such as neighborhood and community environments, and psychopathology. Although these factors have been shown to affect the expression of symptoms of depression and other disorders, little evidence exists of a link between contextual factors and posttraumatic stress disorder (PTSD). The current study tested the relationships among perceived neighborhood disorder (a measure of self-reported perceptions of the physical environment), community cohesion (a measure of perceived social ties), and self-reported PTSD symptoms while controlling for previous trauma exposure in a low-income, urban, African American population. Regression analyses indicated that both neighborhood disorder and community cohesion are related to PTSD symptoms after controlling for trauma exposure. Community cohesion, however, was found to be a partial mediator of the relationship between neighborhood disorder and PTSD symptoms.
\end{abstract}

$\mathbf{T}$ he majority of studies assessing the impact of trauma exposure focuses only on factors at the individual level of analysis (Sampson \& Lauritsen, 1994; Sampson, Morenoff, \& Gannon-Rowley, 2002), despite increasing recognition of the importance of macro-level factors for understanding risk and resilience (Bronfenbrenner, 1979; Coulton \& Korbin, 2007; Jones \& Duncan, 1995; Ross \& Mirowsky, 2001; Sampson \& Groves, 1989). Specifically, individual-level outcomes are not only dependent on individual factors, but also on larger contexts, such as the social and community environment. A growing body of research has examined the relationship between social context and mental health (Aneshensel \& Sucoff, 1996; Browning \& Cagney, 2003; Galea et al., 2006; Linares, 2004; Overstreet \& Braun, 2000; Ross \& Jang, 2000; Ross \& Mirowsky, 2001; Sampson \& Lauritsen, 1994; Silver, Mulvey, \& Swanson, 2002; Weich et al., 2002). However, research that specifically addresses the impact of social context on PTSD symptoms is lacking.

\section{Neighborhood and Community Characteristics}

Characteristics of neighborhoods and communities in which people reside have been shown to be important contextual-level

Correspondence concerning this article should be addressed to Bekh Bradley, Atlanta VA Medical Center, Emory University, 1670 Clairmont Road, Decatur, GA 30033. Electronic mail may be sent to rbrad12@, emory.edu. variables for physical and mental health. Researchers in public health, sociology, and psychology have identified important neighborhood and community characteristics, in addition to emphasizing the need to distinguish between objective characteristics of a neighborhood (e.g., crime rates, population density, etc.) and perceived characteristics of a neighborhood by individuals living in it, e.g., level of safety vs. dangerousness (Jones \& Duncan, 1995; Ross \& Mirowsky, 2001; Sampson \& Groves, 1989).

Ross and Mirowsky (2001) constructed a measure of perceived neighborhood disorder based on respondents' endorsement of statements such as "Vandalism is common in my neighborhood" and "My neighborhood is safe," which they compared to an objective measure of neighborhood characteristics based on census tract data. They argue that economic and neighborhood disadvantage (objective measure) and perceived neighborhood disorder (subjective measure) are different but related constructs. Measures of neighborhood disadvantage are constructed by quantifying "objective" factors such as the percentage of poverty, deviance, crime, vandalism, and drug use. In contrast, perceived neighborhood disorder refers to, " . . . visible cues indicating a lack of order and social control in the community" (Ross \& Mirowsky, 1999, p. 413). This definition relates specifically to signs of order and control as perceived by neighborhood residents. Using these two measures, Ross and Mirowsky (1999) found that perceived neighborhood disorder mediated the relationship between neighborhood disadvantage 
and physical health. Thus, individuals' perception of the context in which they live may be more important than the actual characteristics of the environment.

In addition to objective and perceived characteristics of the physical aspects of neighborhoods, the experience of community within these neighborhoods may affect both physical and mental well-being. The concept of community cohesion refers to the ways that members of a community relate to and provide support for one another (Cutrona, Russell, Hessling, Brown, \& Murray, 2000; Obasaju, Palin, Jacobs, Anderson, \& Kaslow, 2009; Sampson, Raudenbush, \& Earls, 1997). Because these interactions can increase access to resources (Mancini, Martin, \& Bowen, 2005), the concept of community cohesion is similar to both the concept of social support, which generally refers to a more focal set of relationships (e.g. an individual's friends and family), and the concept of social capital, which refers to the broader concept of access to resources (e.g., financial resources, emotional resources, etc.) via social connections. A number of studies have found that social capital (Fitzpatrick, Piko, Wright, \& LaGory, 2005) and social support significantly impact mental and physical health (see Uchino, Cacioppo, \& Kiecolt-Glaser, 1996, for a review of social support and physical health).

\section{Neighborhood Disorder and Mental Health}

Neighborhood characteristics also appear to be related to levels of mental health problems. This is not a new observation: Almost 70 years ago, Faris and Dunham (1939) examined over 30,000 psychiatric hospital admissions records and found high rates of schizophrenia and substance use in the "deteriorated" regions around the urban center of Chicago. Decades later, Ross, Reynolds, and Geis (2000) argued that still little is known about the connections among neighborhood stability, poverty, and psychological well-being. It is surprising, then, that more research has not examined the contextual factors contributing to different mental disorders.

Despite the continuing lag in research, several studies have examined the link between neighborhood factors and incidence of depression. Using the same data that showed perceived neighborhood disorder mediated physical health, Ross (2000) found a link between depressed mood and perceived neighborhood disorder. Specifically, Ross found that while objective neighborhood disadvantage factors (poverty and mother-only households) predicted depression, perceived neighborhood disorder accounted for a significant portion of the relationship.

A prospective study of very low socioeconomic status individuals in inner city Baltimore (Latkin \& Curry, 2003) found a strong association between perceived neighborhood characteristics and subsequent depression. There were also very high rates of substance dependence, with about $47 \%$ having injected illicit drugs in the past 6 months. Even so, there was a robust relationship between perceived disorder and later depression after controlling for depression at baseline.

\section{Perceived Neighborhood Disorder, Community Cohesion, and PTSD}

Although previous studies have established a link between neighborhood disadvantage, perceived neighborhood disorder, and psychopathology, the results thus far have been limited to depression, substance use, and, to a lesser extent, schizophrenia (Silver et al., 2002). No studies to date have explicitly examined the relationship between perceived neighborhood disorder and the incidence of PTSD. This is an important gap in knowledge given the growing number of studies (e.g., Binder et al., 2008; Breslau, Peterson, Poisson, Schultz, \& Lucia, 2004; Schwartz, Bradley, Sexton, Sherry, \& Ressler, 2005; Switzer et al., 1999) indicating that low-income populations living in urban environments are at especially high risk for both exposure to traumatic events and PTSD. For example, a recent study of 617 primary care patients $(96 \%$ of whom were African American) found a $65 \%$ rate of lifetime trauma exposure and a $33 \%$ rate of PTSD (Alim et al., 2006).

An emerging literature on the assessment of neighborhood effects shows promise for contributing to our understanding of PTSD in urban environments. Galea et al. (2006) argued that "at the population level, the contribution of social context to PTSD phenotypic expression may far outweigh the contribution of any given molecular or genotypic determinants" (p. 234). It is firmly established that there are social inequalities in terms of socioeconomic and racial segregation among neighborhoods and that social problems, such as severity of crime, social and physical disorder, and child maltreatment, often correlate with neighborhood disadvantage (Sampson et al., 2002).

One explanation for higher PTSD symptomology in disadvantaged neighborhoods is that mistrust is amplified in those neighborhoods. Ross, Mirowsky, and Pribesh (2001) found that mistrust develops in neighborhoods where individuals perceive threat and feel powerless against it. Moreover, PTSD is characterized by hypervigilance, avoidance, and social withdrawal, which may enhance the fear and mistrust engendered from living in a disadvantaged neighborhood. Ross and Jang (2000) found that informal social ties, a contributing factor in community cohesion, served to reduce fear and mistrust resulting from living in a neighborhood with high perceived disorder, but that participation in formal organizations did not have the same effect. These informal ties are the ones most likely to be interrupted or absent in individuals with PTSD, and therefore perceived neighborhood disorder and lack of community cohesion are likely to exacerbate the fear already present in persons exhibiting symptoms of PTSD. Linares (2004) looked at the impact of social connection and multiple victimization on health outcomes in women living in high crime neighborhoods and found that low social connection was related to poorer health outcomes in general. Specifically, Linares found that having more friends was modestly correlated with having fewer PTSD symptoms. Thus, community cohesion may buffer individuals from the negative effects of neighborhood disadvantage.

In a recent study, Obasaju et al. (2009) found that perceived neighborhood disorder and community cohesion moderate the relationship between childhood emotional abuse and the likelihood of being physically abused as an adult. In addition, the likelihood of being physically abused as an adult was negatively correlated with community cohesion and positively correlated with perceived neighborhood disorder. This study did not take into account an individual's PTSD symptoms. Thus, it remains unclear whether PTSD symptoms are associated with perceived neighborhood disorder and community cohesion. 


\section{Trauma Exposure and Race}

The current study employs a sample from a predominantly low-income, African American population. PTSD is an under recognized phenomenon in low-income, civilian populations. Although the national estimated lifetime rate of PTSD is approximately 7.8\% (Kessler, Sonnega, Bromet, Hughes, \& Nelson, 1995), a study of low-income, predominantly African American patients found a current rate of PTSD of $43 \%$ (Schwartz et al., 2005). Additionally, while Kessler et al. (1995) reported a lifetime trauma exposure rate estimate between $50 \%$ and $60 \%$ for a national sample, Schwartz et al. (2005) found an $83 \%$ rate of lifetime trauma exposure. Finally, individuals with lower socioeconomic status are more likely to experience traumatic events (Alim et al., 2006; Vogel \& Marshall, 2001), and African Americans are more likely to be of lower socioeconomic status (Williams, 1999). For these reasons, it is particularly important from a public health perspective to examine the relationships among perceived neighborhood disorder, community cohesion, and PTSD in a highly traumatized, low-income, predominately African American population.

\section{The Current Study}

Given the strong emerging evidence that contextual factors are associated with psychiatric illnesses, it is important to look at whether perceived neighborhood disorder and community cohesion are related to PTSD symptomology. Though previous research has demonstrated the impact of both neighborhood disorder and community cohesion, only one study has addressed the relation of community cohesion and PTSD, albeit indirectly (Linares, 2004). The current study will examine the relation of community cohesion and perceived neighborhood disorder to PTSD symptoms. It is possible that living in more disordered neighborhoods is related to PTSD symptoms because individuals in these neighborhoods are more likely to experience traumatic stressors such as interpersonal violence (Vogel \& Marshall, 2001). We predict that increased reporting of exposure to traumatic events will be associated with increased reporting of PTSD symptoms. If this is the case, we will control for trauma exposure by including both childhood and adult trauma exposure as a covariate. After controlling for trauma exposure, we predict that perceived neighborhood and community disorder will be related to PTSD symptoms such that higher perceived neighborhood disorder and lower community cohesion will predict higher levels of PTSD symptoms. Finally, we hypothesize that community cohesion will mediate the relationship between neighborhood disorder and PTSD symptoms such that higher levels of community cohesion will buffer the effects of neighborhood disorder.

\section{Method}

\section{Demographics}

The sample consisted of 615 individuals (272 males and 343 females) aged 18 to 81 years $(\mathrm{Mdn}=43)$. The sample is almost exclusively African American (95\%), followed by White $(2.9 \%)$, mixed and other $(0.8 \%$ each), Hispanic or Latino $(0.3 \%)$, and Asian (0.2\%).

\section{Procedure}

Participants were recruited from the General Medical and Obstetric/Gynecological Clinics at a publicly funded, notfor-profit healthcare system that serves the low-income population in Atlanta, Georgia. The clinic population data were primarily collected as part of the Grady Trauma Project, a 5-year National Institutes of Health-funded study of risk and resilience factors related to PTSD. Data were collected over approximately 1 year as part of the ongoing study.

Interviewers approached individuals waiting for appointments and asked if they would like to participate in a study. Of those approached, approximately $58 \%$ agreed to participate. No information was gathered on individuals who declined to participate. It is possible that individuals who declined to participate differed from individuals who agreed, but we are unable to address this question with the current data. Participants were read a consent form and gave verbal and written consent. Participants were then read each question by a trained interviewer who recorded responses on a tablet computer. If called for the appointment before the interview was finished, participants received the full payment of $\$ 15$, and a follow-up interview was scheduled to coincide with the participant's next appointment. Some participants did not complete the measures during the initial meeting and were not available or willing to meet at a later time. Individuals who did not complete the measures are not included in these analyses, and further information was not recorded.

Participants completed a battery of self-report measures which took 45-75 min to complete (dependent in large part on the extent of the participant's trauma history and symptoms). All measures were obtained by verbal interview. Eligibility requirements for all phases of the study included the ability to give informed consent, and the Institutional Review Boards of Emory University School of Medicine and Grady Memorial Hospital approved all procedures used in the study.

\section{Measures}

Demographics Form. The Demographics Form is locally developed and assesses subject age, self-identified ethnicity, relationship status, education, income, and employment status.

Modified PTSD Symptom Scale. (MPSS; Falsetti, Resnick, Resick, \& Kilpatrick, 1993). The MPSS is a 17-item self-report scale assessing PTSD symptomatology over the prior 2 weeks with a range from 0 to 51 for frequency ratings (Coffey, Dansky, Falsetti, Saladin, \& Brady, 1998; Foa \& Tolin, 2000; Foa, Riggs, Dancu, \& Rothbaum, 1993). The MPSS is psychometrically reliable within a 1-month test-retest reliability of $r(93)=.80$ (Foa, Riggs, Dancu, \& Rothbaum, 1993). Frequency items are each rated on a 4-point scale ranging from 0 (not at all) to 3 (5 or more times per week). Consistent with prior literature, we combined these scales to create a continuous measure of overall level of PTSD symptoms (Binder et al., 2008; Schwartz et al., 2005, 2006). Cronbach's alpha for the current sample is .92 . 
Traumatic Events Inventory. (TEI; Schwartz et al., 2005, 2006). The TEI is a 14-item screening instrument for lifetime history of traumatic events. For each traumatic event, the TEI assesses experiencing and witnessing separately, and it also assesses confrontation of traumatic events where appropriate. For the purposes of this study, we only considered traumatic events other than childhood physical or sexual abuse. We scored this instrument by summing the total number of types of traumatic experiences reported by the participants. Although this measure of trauma exposure is not ideal because it does not take into account when the trauma occurred, the frequency of each type of trauma, or the severity of trauma, previous work with this population has indicated that it is an effective estimate of overall trauma exposure (Binder et al., 2008; Davis, Ressler, Schwartz, Stephens, \& Bradley, 2008; Schwartz et al., 2006). Likewise, adult trauma exposure in this sample was significantly correlated with PTSD symptoms as measured by the MPSS $(r=.48)$.

Neighborhood Disorder Scale. (NDS; Ross \& Mirowsky, 1999). The NDS is a 15-item measure intended to assess the perceived physical and social disorder of participants' immediate environment. The scale distinguishes between physical and social order and disorder; however, Ross and Mirowsky (1999) found that overall perceived physical and social disorder represent one concept. Additionally, they found that disorder and order represented two ends of a continuum. The scale has demonstrated strong internal consistency (.92). For this study, we used a total score to create a continuous measure of perceived neighborhood disorder. The Cronbach's alpha for this sample is 89

Community Cohesion Scale. (CCS; Sampson et al., 1997; Simons, Simons, Burt, Brody, \& Cutrona, 2005). Many items for this 20-item scale were taken from the Family and Community Health Study's measure of collective efficacy (Simons et al., 2005), which in turn was adapted from Sampson et al. (1997). Several other items were adapted from the Social Ties Scale (Cutrona et al., 2000). The scale contains items tapping social cohesion and trust, informal social ties, and neighborhood social control. Examples of items include, "When there is a problem around here, the neighbors get together to deal with it," and, "Parents in the neighborhood generally know each other." Sixteen items were rated as true or false. Three items were rated on the following scale: very likely, likely, unlikely, and very unlikely. Finally, 1 item (How easy is it for you to pick out people who are outsiders or who obviously don't live in this area?) was rated on the following scale: very easy, somewhat easy, somewhat difficult, and very difficult. For our sample, the Cronbach's alpha is .86 .

\section{Results}

As discussed, PTSD among low-income, predominately ethnic minority individuals remains an understudied phenomenon. We performed a one-way ANOVA to test whether significant differences existed between African Americans and other ethnic groups for the other demographic variables measured. Because the sample was $95 \%$ African American, we combined all other ethnic groups to increase the sample size of the comparison group. Significant differences were found, with other ethnic groups having completed significantly more schooling, $F(1,610)=11.6, p=.001$, and having experienced more adult traumas $F(1,610)=4.7, p=.03$. For this reason, we chose to exclude other ethnic groups and focus solely on African Americans. The subsample $(N=584)$ was $55.5 \%$ female, had an average age of $40.6(S D=13.6)$, and had an unemployment rate of $66.3 \%$. The majority of the sample did not finish school or only graduated high school $(68.7 \%)$. Accordingly, $39.3 \%$ had a household monthly income below $\$ 500$, and $49.2 \%$ had a monthly income between $\$ 500$ and $\$ 1,999$.

\section{Descriptive Statistics for Trauma, PTSD Symptoms, and Contextual Factors}

Overall, individuals had either experienced or witnessed a high number of traumas as measured by the TEI. Table 1 shows the number of people who experienced or witnessed different traumatic stressors. There appeared to be significant variability in current PTSD symptoms $(M=10.7 ; \quad S D=12.0$; range $=0-51)$. Additionally, the mean for the NDS was 32.9 $(S D=8.7$; range $=15-60)$, and the mean for the CCS was $17.4(S D=6.9$; range $=0-28)$.

\section{Relationships Among Trauma, PTSD Symptoms, and Contextual Factors}

To evaluate our prediction that perceived neighborhood and community cohesion would be related to PTSD symptomology, we first examined bivariate relationships among all relevant variables used for this study (see Table 2). As expected, all the measures were significantly correlated.

Table 1. Trauma Exposure Reported by Type

\begin{tabular}{lrr}
\hline Type of trauma & $N=584$ & Valid \% \\
\hline Natural disaster & 101 & 17.4 \\
Serious accident or injury & 229 & 42.3 \\
Sudden life-threatening illness & 127 & 21.9 \\
Military combat & 22 & 3.8 \\
Close friend or family member murdered & 0 & 0.0 \\
Close friend or family member & 53 & 9.2 \\
$\quad$ committed suicide (witnessed) & 68 & 18.2 \\
Attacked with weapon by spouse or partner & 207 & 35.6 \\
Attacked with weapon by other & 95 & 25.9 \\
Family member or friend attacked & & \\
$\quad$ with weapon (witnessed) & 109 & 29.2 \\
$\quad$ Nonfamily member or friend attacked & & \\
$\quad$ with weapon (witnessed) & 88 & 23.8 \\
Attacked without weapon by spouse or partner & 175 & 30.5 \\
Attacked by other without weapon & 95 & 26.1 \\
Family member or friend attacked & & \\
$\quad$ without weapon (witnessed) & 114 & 31.1 \\
$\quad$ Nonfamily member or friend attacked & & \\
$\quad$ without weapon (witnessed) & 21 & 5.7 \\
Sexual contact with physical force & 155 & 28.1 \\
$\quad$ Other experiences
\end{tabular}

Note. Data derived from self-reported experiences from the Traumatic Events Inventory. Percentages are based on valid data for each question. 
Table 2. Bivariate Correlations Among Trauma and Contextual Variables

\begin{tabular}{lccc}
\hline & NDS & CCS & MPSS \\
\hline NDS & - & & \\
CCS & $-.48^{* *}$ & - & \\
MPSS & $.19^{* *}$ & $-.23^{* *}$ & - \\
Adult Trauma & $.10^{*}$ & $-.10^{*}$ & $.49^{* *}$ \\
\hline
\end{tabular}

Note. $\quad$ NDS $=$ Neighborhood Disorder Scale; $\quad$ CCS $=$ Community Cohesion Scale; MPSS $=$ Modified PTSD Symptoms Scale; Adult Trauma $=$ total number of traumatic stressors (experienced or witnessed) not including childhood on the Traumatic Events Inventory; PTSD $=$ posttraumatic stress disorder.

$* p<.05 . * * p<.01$.

We next used regressions to test a mediational model (Baron \& Kenny, 1986) that posited community cohesion would significantly mediate the relationship between neighborhood disorder and PTSD symptoms (see Figure 1). In these analyses, we partialled out variance due to age and trauma exposure. In line with the first step of meditational analyses, a regression established that neighborhood disorder was significantly predictive of PTSD symptoms, $\beta=.14, t=3.8, p<.001$. A second regression demonstrated that neighborhood disorder was significantly predictive of community cohesion, $\beta=-.45, \quad t=12.3$, $p<.001$. In the final step of mediation analyses, the mediator variable (here, community cohesion) must significantly predict the outcome variable even while controlling for the effects of the primary predictor variable (here, neighborhood disorder). Indeed, community cohesion remained a significant predictor, $\beta=-.13, t=3.2, p=.001$, whereas neighborhood disorder was only marginally significant, $\beta=.08, t=1.9, p=.058$. Table 3 provides the detailed findings of this regression analysis. A Sobel (1982) $Z$-test confirmed that the mediating role of community cohesion was significant, $Z=2.41, p=.016$.

\section{Discussion}

This is the first study to assess directly the associations of perceived neighborhood disorder and perceived community cohesion on self-reported PTSD symptoms. We found that both factors contributed to increased PTSD symptoms in a low-income, African American, urban population. Not only were perceived neighborhood disorder and community cohesion related to

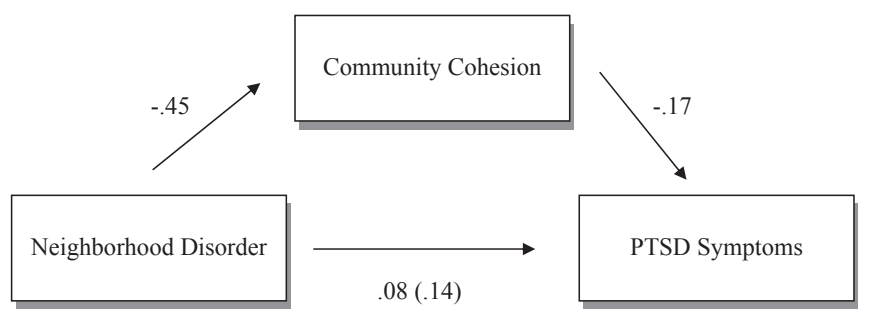

Figure 1. Model demonstrating community cohesion's mediating role between neighborhood disorder and PTSD symptoms (magnitudes reported as betas, controlling for age and adult trauma exposure). PTSD $=$ posttraumatic stress disorder.
Table 3. Hierarchical Regression Results for Final Step of Meditational Analysis

\begin{tabular}{|c|c|c|c|c|c|c|c|}
\hline & $R^{2}$ & $\Delta R^{2}$ & $d f_{1}$ & $d f_{2}$ & $M S_{\text {res }}$ & $\Delta F$ & $p$ \\
\hline Model 1 & .249 & .249 & 2 & 559 & 109.4 & 92.7 & $<.001$ \\
\hline Model 2 & .268 & .019 & 1 & 558 & 106.9 & 14.3 & $<.001$ \\
\hline \multirow[t]{2}{*}{ Model 3} & .281 & .013 & 1 & 557 & 105.1 & 10.2 & .001 \\
\hline & $b$ & $\beta$ & $S E$ & $t$ & $p_{\text {two-tailed }}$ & $r_{\text {zero }}$ & Tolerance \\
\hline \multicolumn{8}{|l|}{ Model 1} \\
\hline Age & -0.08 & -.09 & 0.03 & 2.4 & .018 & .01 & .96 \\
\hline $\begin{array}{l}\text { Adult trauma } \\
\text { exposure }\end{array}$ & 2.1 & .51 & 0.16 & 13.6 & $<.001$ & .49 & .96 \\
\hline \multicolumn{8}{|l|}{ Model 2} \\
\hline Age & -0.06 & -.07 & 0.03 & 1.8 & .074 & .01 & .94 \\
\hline $\begin{array}{l}\text { Adult trauma } \\
\text { exposure }\end{array}$ & 2.1 & .49 & 0.16 & 13.3 & $<.001$ & .49 & .95 \\
\hline $\begin{array}{l}\text { Neighborhood } \\
\text { disorder }\end{array}$ & 0.19 & .14 & 0.05 & 3.8 & $<.001$ & .19 & .97 \\
\hline \multicolumn{8}{|l|}{ Model 3} \\
\hline Age & -0.05 & -.05 & 0.03 & 1.3 & .178 & .01 & .92 \\
\hline $\begin{array}{l}\text { Adult trauma } \\
\text { exposure }\end{array}$ & 2.02 & .48 & 0.16 & 13.0 & $<.001$ & .49 & .94 \\
\hline $\begin{array}{l}\text { Neighborhood } \\
\text { disorder }\end{array}$ & 0.11 & .08 & 0.06 & 1.9 & .058 & .19 & .76 \\
\hline $\begin{array}{l}\text { Community } \\
\text { cohesion }\end{array}$ & -0.23 & -.13 & 0.07 & 3.2 & .001 & -.23 & .75 \\
\hline
\end{tabular}

PTSD symptoms, but community cohesion was shown to significantly mediate the relationship between perceived neighborhood disorder and PTSD symptoms. Overall, our results are in accord with previous studies that have established a link between neighborhood and community factors and mental illness (Aneshensel \& Sucoff, 1996; Browning \& Cagney, 2003; Galea et al., 2006; Linares, 2004; Overstreet \& Braun, 2000; Ross \& Jang, 2000; Ross \& Mirowsky, 2001; Sampson \& Lauritsen, 1994; Silver et al., 2002; Weich et al., 2002). It is noteworthy that perceived neighborhood factors have a significant effect on the expression of PTSD symptoms in our sample even after controlling for the amount of trauma individuals have experienced.

What is especially important is that community cohesion appeared to have a mediating effect on the relationship between neighborhood disorder and PTSD symptoms, which replicates and expands upon Linares's (2004) findings. Specifically, social ties appear again to be an important buffer against the deleterious effects of living in a disordered neighborhood, and though Linares only examined the association of social ties and health outcomes among women, the effect held for a mixed-gender sample. In a study with a similar population, Obasaju et al. (2009) found that both neighborhood disorder and community cohesion moderated the relationship between childhood emotional abuse and intimate partner violence as an adult. However, Obasaju et al. did not test whether community cohesion may have mediated the relationship between neighborhood disorder and intimate partner violence. It may be the case that having a sense of community and strong social ties is more important than the physical characteristics of the neighborhood in preventing intimate partner violence. Women who have stronger social ties may be less likely to stay with an abusive partner because social isolation makes escaping more difficult. 
This study adds to the growing literature on the negative effects of concentrated neighborhood disadvantage. It is especially important because individuals living in these neighborhoods are more likely to experience further traumatic events, which likely further exacerbate PTSD symptoms. Additionally, individuals who experience more negative life events after a traumatic stressor are more likely to develop delayed PTSD (Adams \& Boscarino, 2006). Given the high rate of traumatic stressors in disadvantaged communities, including the higher likelihood of interpersonal violence, increased exposure to drugs, and financial stress, this may be an important causal factor for the high incidence of PTSD symptoms in our sample. However, since our data were not longitudinal, this remains an issue for further study.

\section{Limitations}

There were several limitations to the current study. First and foremost, we relied exclusively on self-report measures. Second, all of our data were collected concurrently; thus, data on trauma exposure are retrospective. It is possible that individuals with PTSD symptoms remember more traumatic experiences or interpret experiences as more traumatic than individuals without PTSD symptoms. To fully understand the relationship between contextual factors such as neighborhood and community disorder, trauma exposure, and PTSD symptoms, longitudinal data are needed. Given the homogeneity of the sample in terms of ethnic make-up, our data do not allow for an understanding of the role of race and social class. These variables are clearly important to a full understanding of social contextual factors and mental health.

Additionally, it must be noted that the sample consisted only of individuals who were seeking treatment at Grady Hospital. Thus, the sample excludes individuals who are not seeking medical care, as well as individuals who utilize other healthcare facilities. However, several studies now indicate that multiple trauma exposure across the lifespan is the rule rather than the exception in samples similar to the one in our study (e.g., low income, urban, high percentage of Black or Latino participants; Alim et al., 2006; Liebschutz et al., 2007; Schilling, Aseltine, \& Gore, 2007) and that multiple trauma exposure is related to increased mental and physical health risk (Breslau, Chilcoat, Kessler, \& Davis, 1999; Green et al., 2000; Schwartz et al., 2006).

\section{Conclusion}

Individuals with PTSD have a fundamental lack of trust. In neighborhoods with visible evidence of crime and degradation, this lack of trust is likely to be exacerbated. Thus, symptoms of PTSD are likely to be worsened by cues in the environment. However, sense of community and social ties may increase trust and decrease hyperarousal. This may be one mechanism underlying the buffering role of community cohesion. Although it is undoubtedly important to address the physical characteristics of neighborhoods, the current study suggests that the most efficacious intervention point may be in fostering community ties. Intervening at the community level may lead to better health outcomes, less PTSD symptomology, and less disordered neighborhoods.
Understanding risk and resilience in response to multiple trauma exposure is of high public health importance. Despite the limitations of our study, we believe that it is an important step in incorporating social and contextual factors into the study of PTSD. Future research must extend these findings to other populations in order to better understand how to address these challenges. This study demonstrates intervening to treat PTSD at an individual level may not be enough. Instead, the problems of concentrated poverty and violence will need to be addressed at a more macro level, to decrease the near-epidemic levels of civilian PTSD within impoverished inner-city communities.

Keywords: low-income African American adults; mediational model; PTSD; trauma; risk and resilience; ecological factors; neighborhood characteristics; community cohesion

\section{References}

Adams, R. E., \& Boscarino, J. A. (2006). Predictors of PTSD and delayed PTSD after disaster: The impact of exposure and psychosocial resources. Journal of Nervous and Mental Disease, 194, 485493.

Alim, T. N., Graves, E., Mellman, T. A., Aigbogun, N., Gray, E., Lawson, W., \& Charney, D. S. (2006). Trauma exposure, posttraumatic stress disorder and depression in an African-American primary care population. Journal of the National Medical Association, 98, 1630-1636.

Aneshensel, C. S., \& Sucoff, C. A. (1996). The neighborhood context of adolescent mental health. Journal of Health and Social Behavior, 37, 293-310.

Baron, R. M., \& Kenney, D. A. (1986). The moderator-mediator variable distinction in psychological research: Conceptual, strategic, and statistical considerations. Journal of Personality and Social Psychology, 51, 1173-1182.

Binder, E. B., Bradley, R. G., Liu, W., Epstein, M. P., Deveau, T. C., Mercer, K. B., \& Ressler, K. J. (2008). Association of FKBP5 polymorphisms and childhood abuse with risk of posttraumatic stress disorder symptoms in adults. Journal of the American Medical Association, 299, 1291-1305.

Breslau, N., Chilcoat, H. D., Kessler, R. C., \& Davis, G. C. (1999). Previous exposure to trauma and PTSD effects of subsequent trauma: Results from the Detroit Area Survey of Trauma. American Journal of Psychiatry, 156, 902-907.

Breslau, N., Peterson, E. L., Poisson, L. M., Schultz, L. R., \& Lucia, V. C. (2004). Estimating post-traumatic stress disorder in the community: Lifetime perspective and the impact of typical traumatic events. Psychological Medicine, 34, 889-898.

Bronfenbrenner, U. (1979). The ecology of human development: Experiments by nature and design. Cambridge, MA: Harvard University Press.

Browning, C. R., \& Cagney, K. A. (2003). Moving beyond poverty: Neighborhood structure, social process, and health. Journal of Health and Social Behavior, 44, 552-571.

Coffey, S. F., Dansky, B. S., Falsetti, S. A., Saladin, M. E., \& Brady, K. T. (1998). Screening for PTSD in a substance abuse sample: Psychometric properties of a modified version of the PTSD Symptom Scale Self-Report. Journal of Traumatic Stress, 11, 393-399.

Coulton, C. J., \& Korbin, J. E. (2007). Indicators of child well-being through a neighborhood lens. Social Indicators Research, 84, 349-361.

Cutrona, C. E., Russell, D. W., Hessling, R. M., Brown, P. A., \& Murray, V. (2000). Direct and moderating effects of community context 
on the psychological well-being of African American women. Journal of Personality and Social Psychology, 79, 1088-1101.

Davis, R. G., Ressler, K. J., Schwartz, A. C., Stephens, K. J., \& Bradley, R. G. (2008). Treatment barriers for low-income, urban African Americans with undiagnosed posttraumatic stress disorder. Journal of Traumatic Stress, 21, 218-222.

Falsetti, S. A., Resnick, H. S., Resick, P. A., \& Kilpatrick, D. (1993). The modified PTSD symptom scale: A brief self-report measure of posttraumatic stress disorder. The Behavioral Therapist, 16, 161-162.

Faris, R., \& Dunham, W. (1939). Mental disease in urban areas. Chicago, IL: University of Chicago Press.

Fitzpatrick, K. M., Piko, B. F., Wright, D. R., \& LaGory, M. (2005). Depressive symptomatology, exposure to violence, and the role of social capital among African American adolescents. American Journal of Orthopsychiatry, 75, 262-274.

Foa, E. B., Riggs, D. S., Dancu, C. V., \& Rothbaum, B. O. (1993). Reliability and validity of a brief instrument for assessing post-traumatic stress disorder. Journal of Traumatic Stress, 6, 459-473.

Foa, E. B., \& Tolin, D. F. (2000). Comparison of the PTSD Symptom Scale: Interview Version and the Clinician-Administered PTSD Scale. Journal of Traumatic Stress, 13, 181-191.

Galea, S., Acierno, R., Ruggiero, K., Resnick, H., Tracy, M., \& Kilpatrick, K. (2006). Social context and the psychobiology of posttraumatic stress. Annals of the New York Academy of Sciences, 1071, 231-241.

Green, B. L., Goodman, L. A., Krupnick, J. L., Corcoran, C. B., Petty, R. M., Stockton, P., \& Stern, N. M. (2000). Outcomes of single versus multiple trauma exposure in a screening sample. Journal of Traumatic Stress, 13, 271-286.

Jones, K., \& Duncan, C. (1995). Individuals and their ecologies: Analyzing the geography of chronic illness within a multilevel modeling framework. Health and Place, 1, 27-30.

Kessler, R., Sonnega, A., Bromet, E., Hughes, M., \& Nelson, C. B. (1995). Posttraumatic stress disorder in the National Comorbidity Survey. Archives of General Psychiatry, 52, 1048-1060.

Latkin, C. A., \& Curry, A. D. (2003). Stressful neighborhoods and depression: A prospective study of the impact of neighborhood disorder. Journal of Health and Social Behavior, 44, 34-44.

Liebschutz, J., Saitz, R., Brower, V., Keane, T. M., Lloyd-Travaglini, C., Averbuch, T., \& Samet, J. H. (2007). PTSD in urban primary care: High prevalence and low physician recognition. Journal of General Internal Medicine, 22, 719-726.

Linares, L. O. (2004). Social connection to neighbors, multiple victimization, and current health among women residing in high crime neighborhoods. Journal of Family Violence, 19, 355-366.

Mancini, J. A., Bowen, G. L., \& Martin, J. A. (2005). Community social organization: A conceptual linchpin in examining families in the context of communities. Family Relations, 54, 570-582.

Obasaju, M. A., Palin, F. L., Jacobs, C., Anderson, P., \& Kaslow, N. J. (2009). Won't you be my neighbor? Using an ecological approach to examine the impact of community on revictimization. Journal of Interpersonal Violence, 24, 38-53.

Overstreet, S., \& Braun, S. (2000). Exposure to community violence and posttraumatic stress symptoms: Mediating factors. American Journal of Orthopsychiatry, 70, 263-271.

Ross, C. E. (2000). Neighborhood disadvantage and adult depression. Journal of Health and Social Behavior, 41, 177-187.

Ross, C. E., \& Jang, S. J. (2000). Neighborhood disorder, fear, and mistrust: The buffering role of social ties with neighbors. American Journal of Community Psychology, 28, 401-420.

Ross, C. E., \& Mirowsky, J. (1999). Disorder and decay: The concept and measurement of perceived neighborhood disorder. Urban Affairs Review, 34, 412-432.
Ross, C. E., \& Mirowsky, J. (2001). Neighborhood disadvantage, disorder, and health. Journal of Health and Social Behavior, 42, 258-276.

Ross, C. E., Mirowsky, J., \& Pribesh, S. (2001). Powerlessness and the amplification of threat: Neighborhood disadvantage, disorder, and mistrust. American Sociological Review, 66, 568-591.

Ross, C. E., Reynolds, J. R., \& Geis, K. J. (2000). The contingent meaning of neighborhood stability for residents' psychological well-being. American Sociological Review, 65, 581-597.

Sampson, R. J., \& Groves, W. B. (1989). Community structure and crime: Testing social-disorganization theory. Journal of Sociology, 94, 774-802.

Sampson, R. J., \& Lauritsen, J. L. (1994). Violent victimization and offending: Individual-, situational-, and community-level risk factors. In J. A. Reiss \& J. A. Roth (Eds.), Understanding and preventing violence: Social influences (pp. 1-114). Washington, DC: National Academy Press.

Sampson, R. J., Morenoff, J. D., \& Gannon-Rowley, T. (2002). Assessing "neighborhood effects": Social processes and new directions in research. Annual Review of Sociology, 28, 443-478.

Sampson, R. J., Raudenbush, S. W., \& Earls, F. (1997). Neighborhoods and violent crime: A multilevel study of collective efficacy. Science, New Series, 277, 918-924.

Schilling, E., Aseltine, R., \& Gore, S. (2007). Adverse childhood experiences and mental health in young adults: A longitudinal survey. $B M C$ Public Health, 7, 30. doi: 10.1186/1471-2458-7-30.

Schwartz, A. C., Bradley, R., Penza, K. M., Sexton, M., Jay, D., Haggard, P. J., \& Ressler, K. J. (2006). Pain medication use among patients with posttraumatic stress disorder. Psychosomatics, 47, $136-142$.

Schwartz, A. C., Bradley, R. L., Sexton, M., Sherry, A., \& Ressler, K. J. (2005). Posttraumatic stress disorder among African Americans in an inner city mental health clinic. Psychiatric Services, 56, 212-215.

Silver, E., Mulvey, E. P., \& Swanson, J. W. (2002). Neighborhood structural characteristics and mental disorder: Faris and Dunham revisited. Social Science \& Medicine, 55, 1457-1470.

Simons, R. L., Simons, L. G., Burt, C. H., Brody, G. H., \& Cutrona, C. (2005). Collective efficacy, authoritative parenting, and delinquency: A longitudinal test of a model integrating community- and familylevel processes. Criminology, 43, 989-1029.

Sobel, M. E. (1982). Asymptotic confidence intervals for indirect effects in structural equation models. In S. Leinhart (Ed.), Sociological Methodology (pp. 290-312). San Francisco, CA: JosseyBass.

Switzer, G. E., Dew, M. A., Thompson, K., Goycoolea, J. M., Derricott, T., \& Mullins, S. D. (1999). Posttraumatic stress disorder and service utilization among urban mental health center clients. Journal of Traumatic Stress, 12, 25-39.

Uchino, B. N., Cacioppo, J. T., \& Kiecolt-Glaser, J. K. (1996). The relationship between social support and physiological processes: A review with emphasis on underlying mechanisms and implications for health. Psychological Bulletin, 119, 488-531.

Vogel, L. C., \& Marshall, L. L. (2001). PTSD symptoms and partner abuse: Low income women at risk. Journal of Traumatic Stress, 14 $569-584$.

Weich, S., Blanchard, M., Prince, M., Burton, E., Erens, B., \& Sproston, K. (2002). Mental health and the built environment: Crosssectional survey of individual and contextual risk factors for depression. British Journal of Psychiatry, 180, 428-433.

Williams, D. (1999). Race, socioeconomic status and health. Annals of the New York Academy of Science, 896, 173-188. 